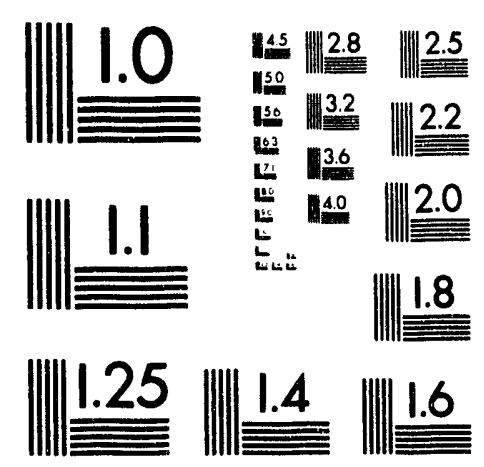



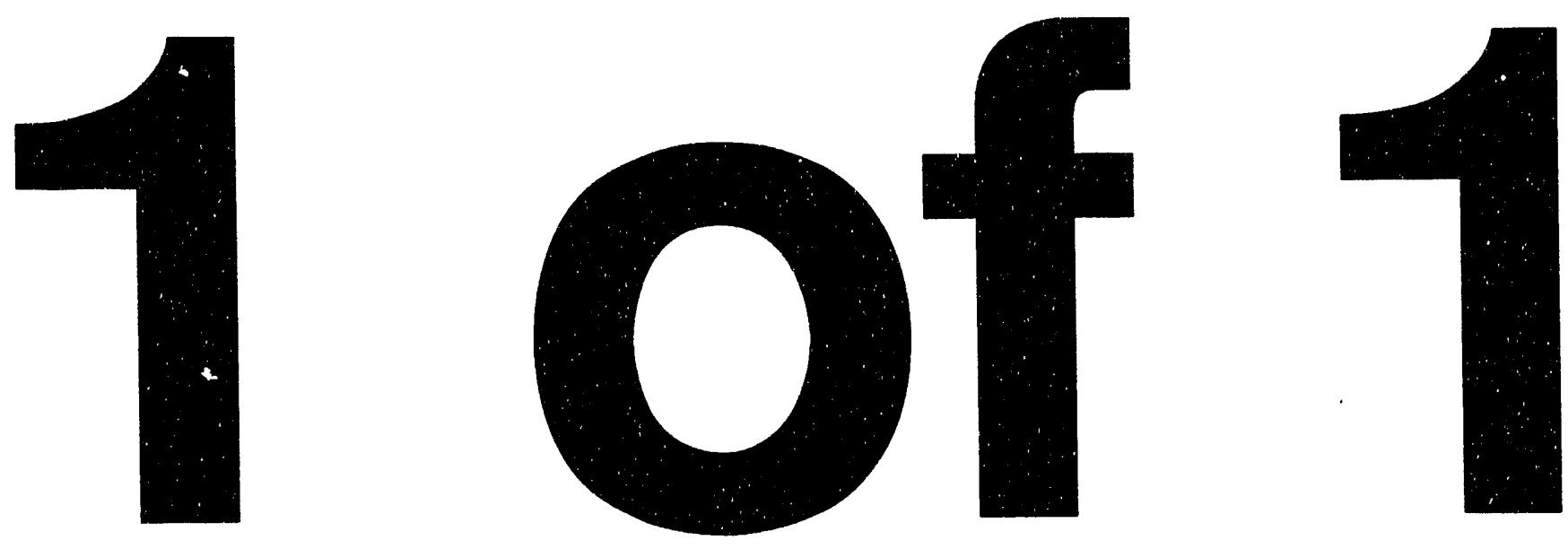


\title{
Ground-Penetrating Imaging Radar Development for Bridge Deck and Road Bed Inspection
}

\author{
J. P. Warhus \\ J. E. Mast \\ S. D. Nelson \\ E. M. Johansson
}

May 1993

This is an informal report intended primarily for internal or limited external distribution. The opinions and conclusions stated are those of the author and may or may not be those of the Laboratory.

Work performed under the auspices of the U.S. Department of Energy by the Lawrence Livermore National Laboratory under Contract W-7405-Eng-48. 


\section{DISCLAIMER}

This document was prepared as an account of work sponsored by an agency of the United States Government. Neither the United States Government nor the University of California nor any of their employees, makes any warranty, express or implied, or assumes any legal liability or responsibility for the accuracy, completeness, or usefulness of any information, apparatus, product, or process disclosed, or represents that its use would not infringe privately own rights. Reference herein to any specific commercial products, process, or service by trade name, trademark, manufacturer, or otherwise, does not necessarily constitute or imply its endorsement, recommendation, or favoring by the United States Government or the University of California. The views and opinions of authors expressed herein do not necessarily state or reflect those of the United States Government or the University of California, and shall not be used for advertising or product endorsement purposes.

This report has been reproduced directly from the best available copy.

Available to DOE and DOE contractors from the

Office of Scientific and Technical Information

P.O. Box 62, Oak Ridge, TN 37831

Prices available from (615) 576-8401, FTS 626-8401

Available to the public from the

National Technical Information Service

U.S. Department of Commerce

5285 Port Royal Road

Springfield, VA 22161 


\title{
Ground-Peneír ating Imaging Radar Development for Bridge Deck and Road Bed Inspection*
}

\author{
Microwave \& Pulsed Power Thrust Area \\ Technical Planning Document
}

MPPTA-TPD-93-1

\author{
Prepared by \\ J.P. Warhus \\ J.E. Mast \\ S.D. Nelson \\ E.M. Johansson \\ Electronic Engineering Department \\ Lawrence Livermore National Laboratory \\ Livermore, California
}




\title{
Ground-Penetrating Imaging Radar Development for Bridge Deck and Road Bed Inspection
}

\author{
J.P. Warhus \\ J.E. Mast \\ S.D. Nelson \\ E.M. Johansson \\ Electronics Engineering Department \\ Lawrence Livermore National Laboratory \\ P.O. Box 808, M/S L-228, Livermore, CA 94551
}

\section{Summary}

Ground-penetrating imaging radar (GPIR) is proposed for large-area inspection of concrete and concrete/asphalt composite bridge decks and roadways. This technique combines ground-penetrating radar (GPR) with unique image reconstruction algorithms developed for identification and characterization of subsurface flaws and structural features. New data acquisition hardware and image reconstruction techniques, under development at LLNL, offer the possibility for reliable and efficient, high-resolution subsurface imaging through the use of improved ultra-wideband transmitters, antennas, and arrays, and enhanced image- and signal-processing software. A field test of a limited-capability prototype system is planned for FY-93, as is completion of a conceptual design for a practical inspection system. A follow-on program for FY-94 would focus on development and demonstration of an advanced bridge inspection system prototype based on the conceptual design completed during FY-93.

\section{Introduction}

GPR technology has been used in a broad range of applications-from archeological and geophysical exploration, to detection of ground vater, buried hazardous waste, and underground cavities and tunnels, and inspection and evaluation of civil structures. In the typical civil structure inspection application, inspectors have utilized GPR to locate structural features like reinforcing bars or tensioning cables in order to prevent damaging or weakening the structure while collecting core samples for inspection or during rehabilitation or renovation operations.

In recent research applications, GPR was evaluated to determine its ability to accurately and rapidly characterize the condition of roadbeds and bridge decks to establish needs for maintenance or repair. In one study, a vehicle-mounted GPR was used to assess the condition of asphalt-overlaid bridge decks in New Hampshire. Deck condition was predicted using a thresholding technique based on the statistical variation of the computed dielectric constant of the deck concrete and known deck conditions. Overall condition was characterized as a percentage of the deck area that was deteriorated; specific locations of deterioration were not identified. Subsequent destructive inspection of several bridges included in the study, while under repair or replacement, showed that this technique produced accurate results $93 \%$ of the time for those bridges. ${ }^{1}$ Another study used GPR to measure asphalt layer and granular base thickness in roadways, at speeds up to 40 miles per hour. In this study, measurement tolerances of $+/-0.32$ inch for asphalt layers and $+/-1.0$ inch for base layers were reported. Measured thickness data were used to improve measurement accuracy for detecting voids under pavement using falling weight deflectometry. ${ }^{2}$ 
Those investigations show that GPR, when integrated with appropriate computers and software, can improve the efficiency and accuracy of inspection methods for roadbeds and bridge decks. However, the techniques used in cach case produce data of limited usefulness for detailed and overall condition assessments. In both cases GPR data were collected for confined areas of the bridge deck or roadway-typically, in the vehicle wheel paths. Measurements and calculations over these small areas were used to extrapolate the overall deck or roadbed condition-estimate based on layer reflectivity. While the most severe wear and damage occurs in the wheel paths, condition assessments for adjacent areas are needed to provide accurate estimates of overall deterioration. In addition, data reduction techniques used in these studies do not provide enough information to locate or map damaged areas or to identify the type of damage. That information is required if economical repairs, short of major restoration or replacement, are to be implemented. Finally, in both studies, only the dorvn-range (depth) resolving capabilities of GPR were used to assess roadbed or deck conditions; significant additional data can be obtained from GPR surveys if cross-range (transverse) resolving capabilities are also used.

In an improved roadbed or bridge deck inspection system, such as the one under preliminary development here, a mobile GPR gathers data for later high-resolution image reconstruction of embedded defects and features. High-quality images allow visualization of structure internals, permitting evaluation of condition with data that usually is obtainable only with destructive techniques. The proposed performance enhancements are achieved by the application of advanced hardware and software. Traffic-lane-wide coverage is made possible through the use of new transmitters, antennas, and large-aperture receiving arrays. High-speed data acquisition and accompanying inspection vehicle speed is enabled with multiple receiver channels using state-of-the-art data transmission and storage equipment. Overall resolution is improved by increased transmitter pulse bandwidth and enhanced antenna performance. Cross-ranging capabilities are exploited by applying synthetic aperture radar data processing techniques to produce 3-dimensional spatial images. These advancements in GPR technology can ensure adequate data collection for estimating overall deck condition and localizing and characterizing damaged areas.

\section{Advanced Ground-Penetrating Imaging Radar (GPIR) Concept Description}

In the ongoing development work, we developed an inspection system concept and established performance requirements based on a baseline set of system operational guidelines. ${ }^{3}$ These guidelines included:

- Vehicle moves over bridge deck at $\sim 30$ mph during inspections.

- Data acquired for one traffic-lane-ivide sivath of deck per vehicle pass.

- Deck structures inspected to a depth of 1.5 feet, maximum.

- Limited real-time data display to permit operators to evaluate inspection data quality.

- Off-line image reconstruction, at rates permitting imaging 10 or more typical bridges (four lanes wide, 150 feet long) per day.

- Images reconstructed in 3-dimensions, with resolution of 2 to 4 inches.

As shown in Figure 1 an inspection vehicle equipped with a transmitting antenna and a linear array of receivers travels over the road or bridge deck surface, sweeping out a traffic-lane-wide synthetic aperture. Data recorded from the receivers is transferred via multiple data streams to a mass data storage subsystem, from which it can be accessed for image reconstruction. Very high-speed image processors in the vehicle, or at centrally located processing centers, reconstruct images of the bridge deck structure for evaluation by a bridge inspector. High-resolution images for a typical bridge are reconstructed in less than one hour.

Mobile inspection data acquisition, at speeds approaching highway speed limits, will permit rapid and costeffective evaluation of large areas of bridge decks and roadbeds. Assessment of reconstructed images produced from the radar data will permit inspectors to determine bridge deck or roadbed conditions and prioritize maintenance and repair activities and expenditures on the basis of high-quality inspection data. 


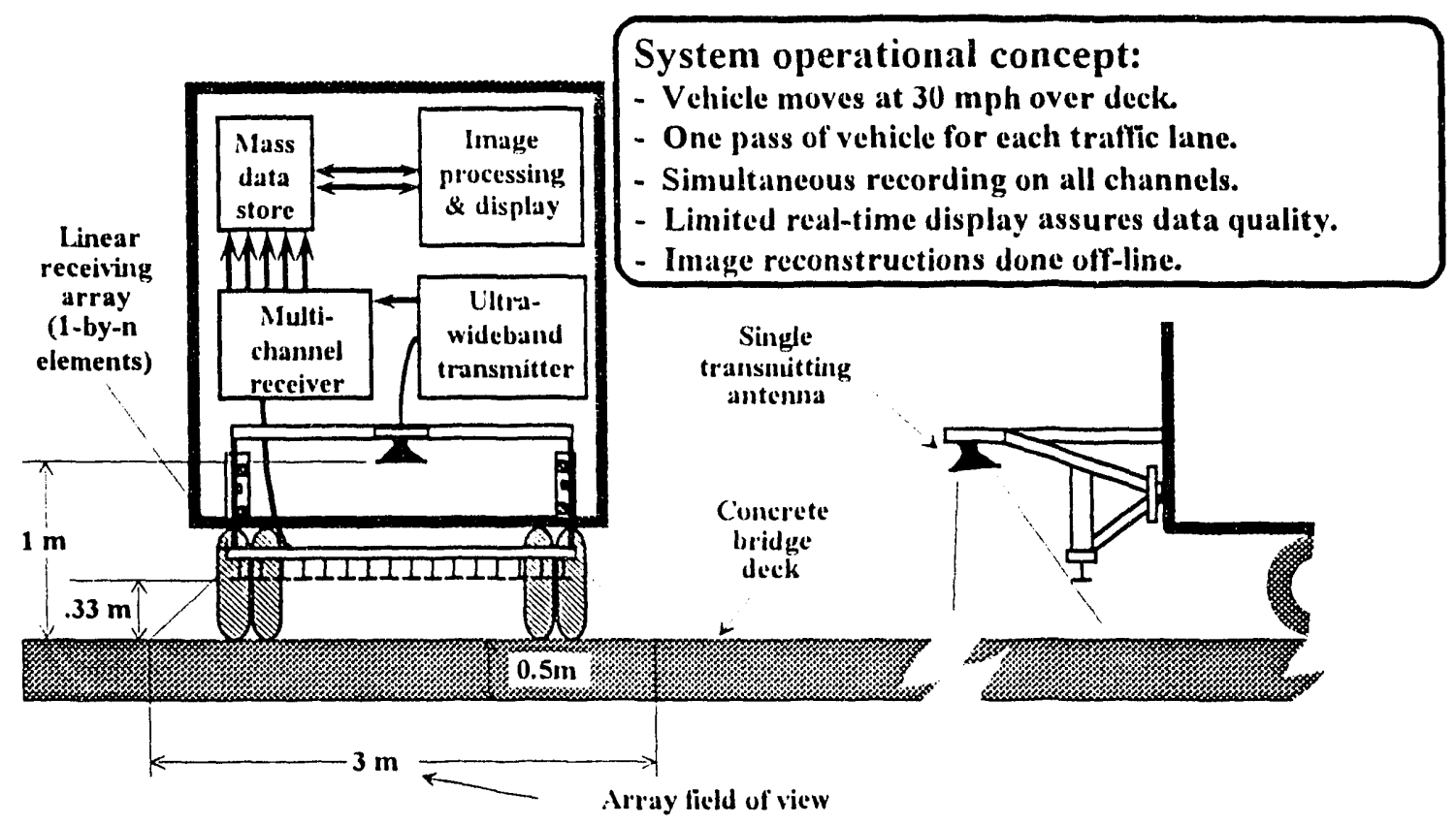

Figure 1. Proposed GPIR bridge inspection concept.

A. more detailed system-level concept is illustrated in a block diagram in Figure 2. Key system requirements established for this design include: receiver dynamic range and minimum discernible signal (MDS); the number of receiving channels (and array elements) required to achieve the desired traffic-lanewidth coverage and image resolution; peak and average transmitter power; transmitted waveform characteristics; transmitting antenna characteristics; pulse repetition frequency (PRF); data acquisition and transfer rates; and computational power required to provide efficient image reconstruction turn-around.

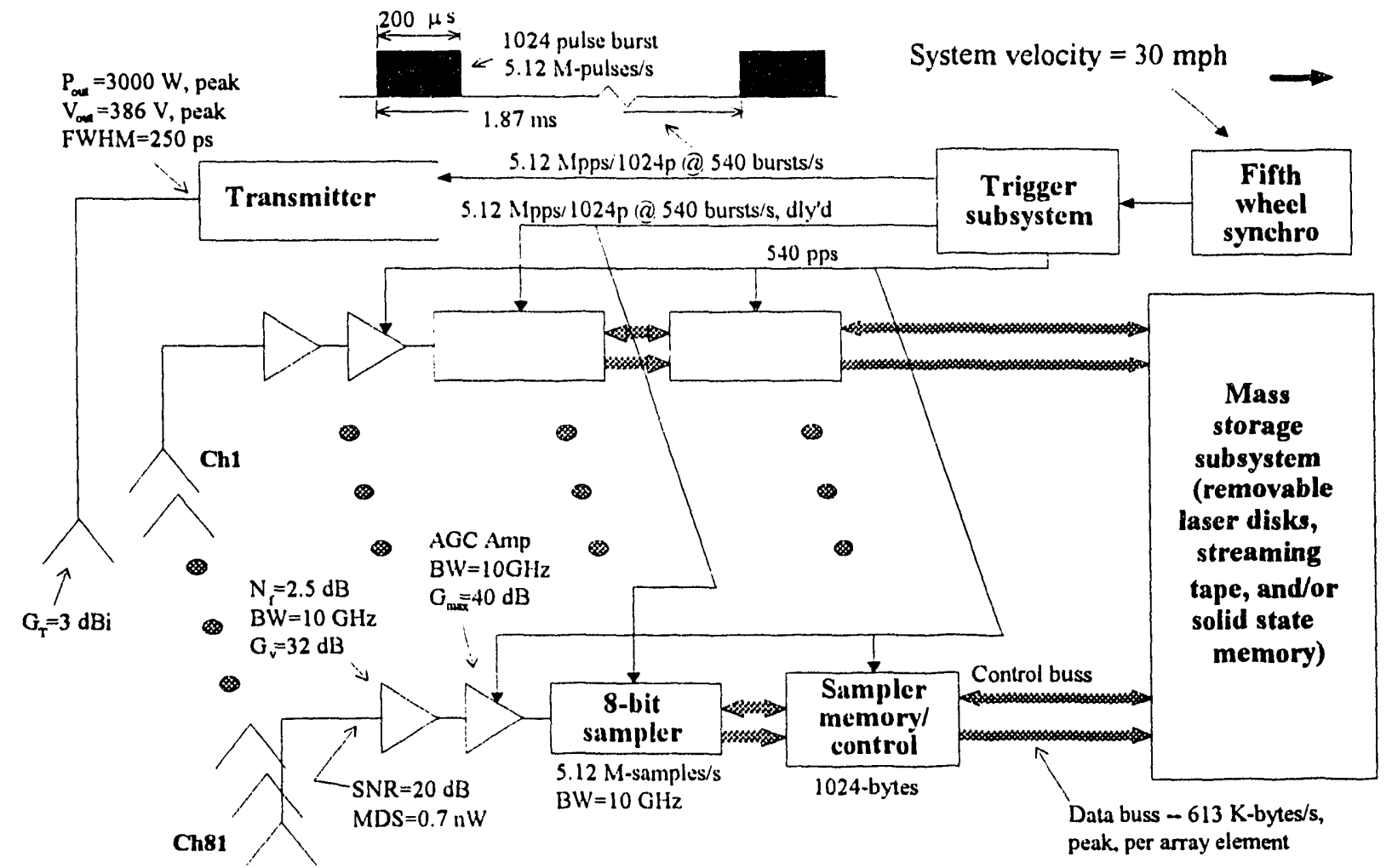

Figure 2. Proposed GPIR block diagram. 


\section{FY-93 Program Plan}

The thrust of the current effort at LLNL is to develop and validate system and subsystem concepts for an advanced GPIR capable of providing high-resolution images of bridge decks, roadbeds, and other civil structures. This is the second year of this continuing program. Our FY-93 goals are to design, test, evaluate, and demonstrate several important system elements required to implement a roadbed and bridge deck inspection system.

Key development tasks identified for work in FY-93 include: experimental validation of electromagnetic modeling and imaging algorithm performance; design, optimization, and test of wideband transmitters, antennas, and arrays; development and refinement of image reconstruction and enhancement techniques; and definition of requirements for ultra-wideband (UWB) transmitters, receivers, antennas, and arrays, and for multi-channel, parallel data acquisition, computation, and storage.

The FY-93 work will culminate in a field test of a limited-capability prototype of the inspection system designed to demonstrate technology advancements and improverments developed under this program. We plan to conduct the test in coordination with the California State Department of Transportation (CalTrans) on an existing bridge deck or other similar concrete structure. The test will be designed to demonstrate the feasibility of the hardware and software concepts developed in the program. Budget constraints will limit prototype performance: for example, data acquisition rates and image turn-around time will not be at levels required for an operational inspection system.

Finally, a conceptual design for a practical inspection system will be completed in FY-93. The design will include estimates of expected performance and cost and a development schedule, and it will be used as the basis for a proposal for final developmental work for which we will seek outside funding.

A follow-on program for FY-94 would focus on development and demonstration of an operational bridge inspection system based on the conceptual design completed during FY-93. The overall scope and schedule for the effort could be scaled to match budgetary constraints. This program could be coordinated with CalTrans, with a demonstration on an existing highway structure.

\section{Resources}

Our existing GPR capabilities include a laboratory dedicated to testing and evaluating GPR hardware, and computer and related facilities needed to support modeling, signal processing and image reconstruction, and visualization needs. In addition, the program has access to other LLNL facilities, including antenna test ranges and anechoic chambers, super-computers, and a variety of engineering workstations. The program is directly supported by personnel with extensive experience in analysis, design, development, and testing of radar systems, electromagnetics and antennas, and signal processing and imaging algorithms. In addition, laboratory personnel not directly associated with the program and outside consultants are available for consultation on a variety of related issues and for program review.

The GPR laboratory is equipped with both standard and special test equipment needed to support UWB radar experimentation and data acquisition. Standard test equipment includes oscilloscopes, impulse generators, UWB microwave amplifiers, power supplies, motor controllers, meters, etc. Specialized equipment, developed under the ongoing program, includes impulse generators and transmitting and receiving antennas designed specifically for the inspection application. Data acquisition and control hardware used in experiments are under the control of a dedicated instrument control computer.

A test bed, designed to provide a realistic test object during early development, is set up in the laboratory. The test bed, shown in Figure 3 before concrete was poured, is a concrete slab containing reinforcing bars, 


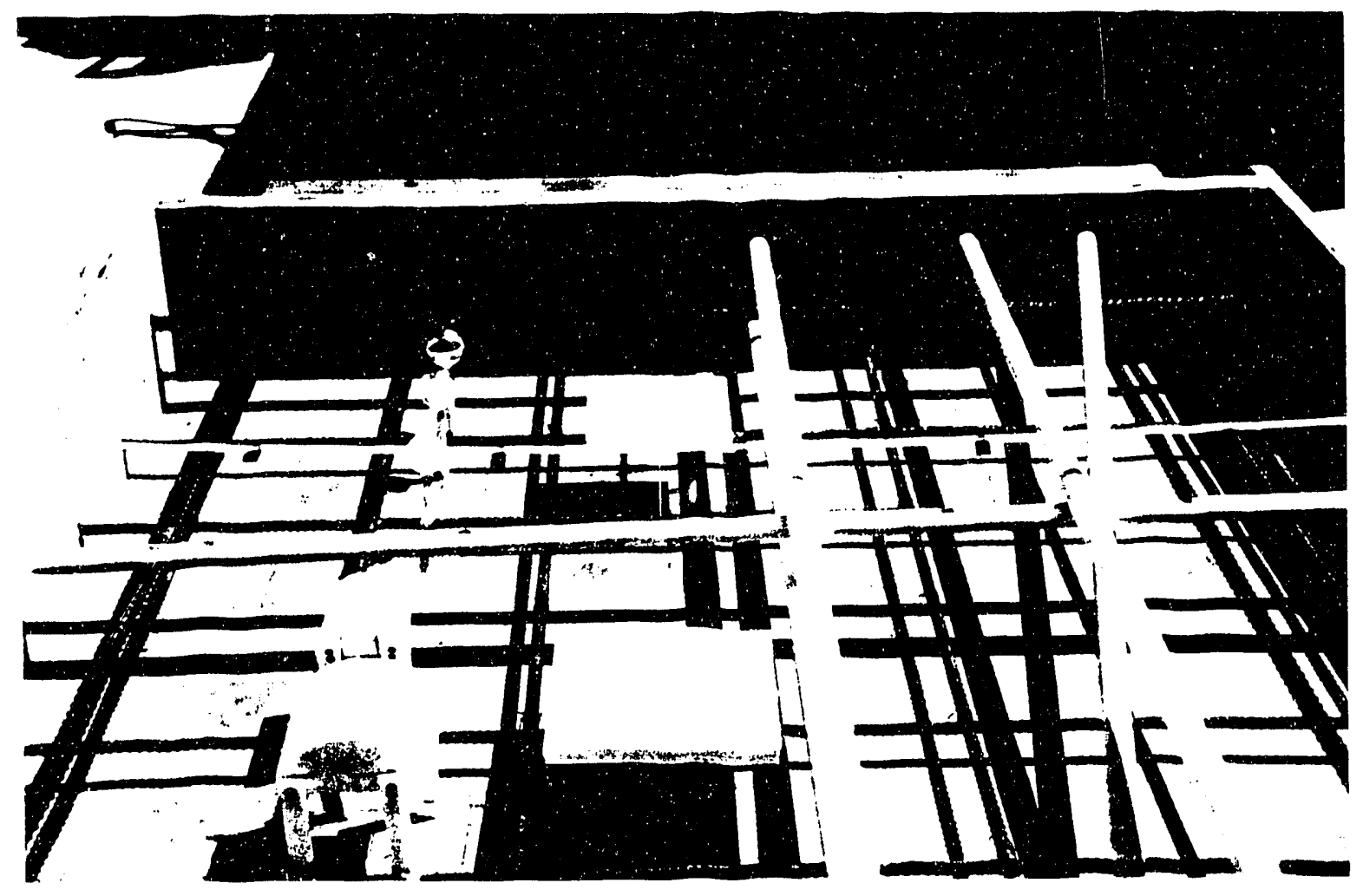

Figure 3. Test bed prior to concrete pour.

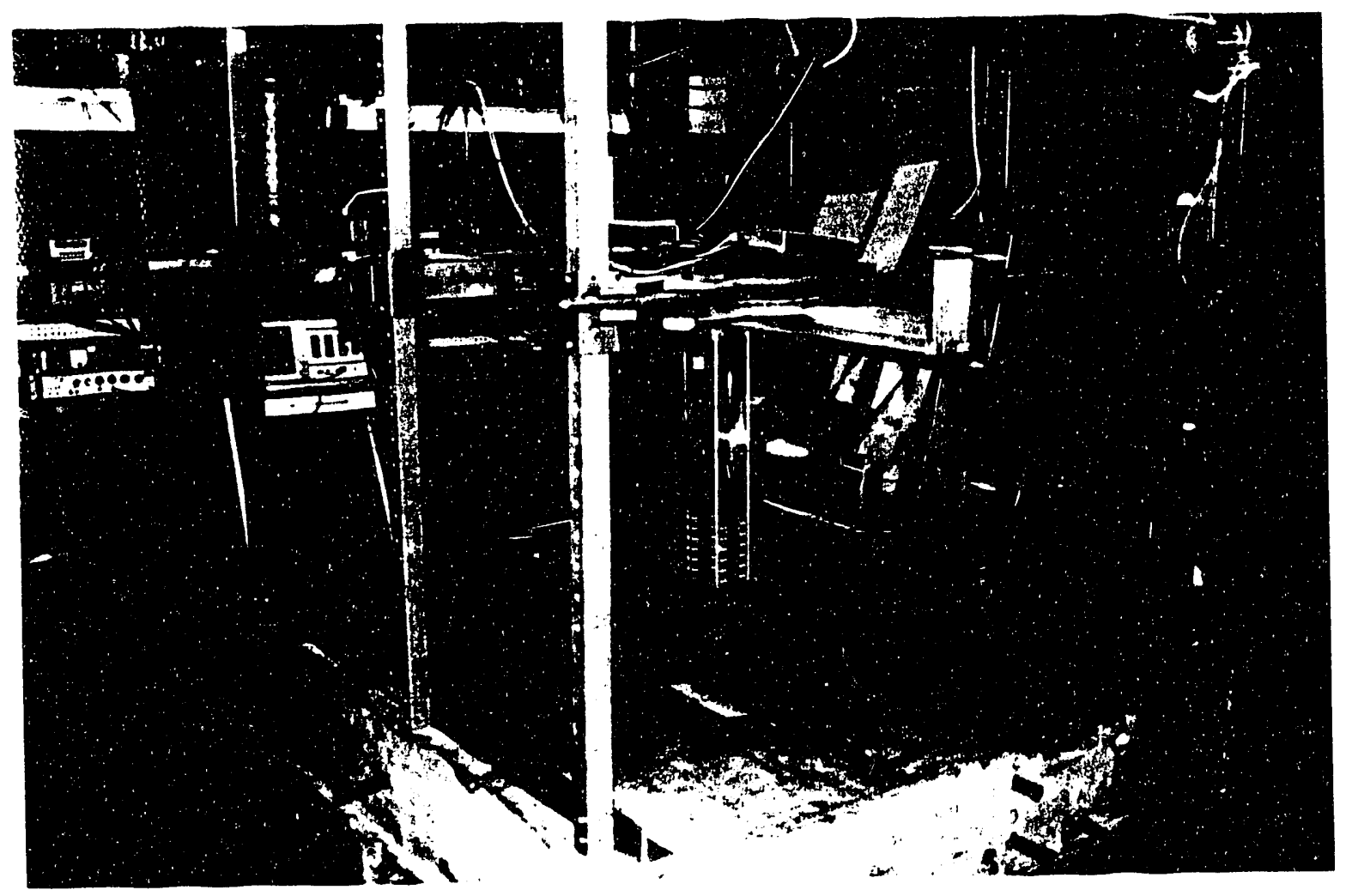

Figure 4. The GPR laboratory showing a typical experimental setup 
both fixed and removable, and other objects designed to provide a means for evaluating data acquisition and imaging performance. Concrete poured in the test bed was prepared and handled in accordance with specifications used by CalTrans for concrete bridges. The test bed is equipped with motor-driven slide mechanisms designed to permit antennas to be accurately and repeatably moved over the slab, simulating both the movement of an inspection vehicle over a roadbed or bridge deck and the linear array of receiving antennas mounted on the vehicle. A typical experimental setup in the GPR laboratory is shown in Figure 4. The setup shown includes the test bed, and some standard and specialized equipment that is routinely used.

\section{Recent Results}

In recent testing, we collected data and reconstructed the first images of features embedded within our test bed. In these experiments, we collected data using a monostatic antenna configuration (i.e., transmitting and receiving antennas collocated) driven by a very low-power impulse generator (approximately 1 watt of peak power). The antennas were mounted on a stepper-motor-driven slider, with the antenna aperture about 2 inches above the concrete surface, and moved over an area of the slab while data was collected at $1 / 2$ inch spatial intervals.

Figure 5 shows a sequence of 2-dimensional images which are planar slices from a 3-dimensional image reconstruction; the slices are parallel to the surface of the concrete. The depth calculated in the reconstruction is indicated for each frame. The sequence starts near the concrete surface (Frame $A$ ) and progresses through the volume. Within the imaged volume are four cylindrical voids; these voids are in locations where removable reinforcing bars (rebars) have been removed. The first two voids are parallel with each other, with top surfaces about 2.5 inches below and nearly parallel with the concrete surface. One of the voids, at the top of the image, is only partially visible in Frames $C$ through $E$; the other is visible in Frames B through E. The third void is beneath (at a depth of about 3.7 inches below the surface) and perpendicular to the first two, and it slopes slightly deeper into the concrete at the end near the top of the image. In Frame D, near the bottom of the frame, the third void first appears, and it is visible in Frames D through $\mathrm{G}$. The difference in depth, within the image, from one end of the third void to the other is approximately 0.7 inches; its sloping orientation is evident in the image sequence. A portion of the fourth void is visible in the lower right corner of Frames $\mathrm{G}$ and $\mathrm{H}$ of the sequence. This void starts at a depth of about 4.6 inches and slopes deeper into the concrete and slightly toward the top of the frame. Because of the low output power of the impulse generator used in this experiment, scattered signal power was too low to permit detection of objects deeper than about 4.5 inches in the concrete.

Figure 6 shows a similar sequence of 2-dimensional planar slices from another experiment. Data were collected over the same area of the test bed, but the size and shape of the area were altered slightly to include a more complete view of features near the concrete surface. For this experiment, rebars were installed in three of the cylindrical voids shown in the previous example. In one of the voids nearest the surface, rebars were installed to form a 4-inch air gap in the imaged area. The first two parallel rebars begin to appear in Frame B and are visible through Frame $E$. The rebar near the top of the image has the air gap clearly visible in Frames $\mathrm{C}$ through $\mathrm{E}$. Although they are the same size (1-inch diameter), the images of the parallel rebars do not have the same intensity. This difference is a result of the rebars having different scattering cross sections; instead of being round, the rebars have a somewhat oval shape which makes their cross sections orientation-dependent. The rebars used to form the 4-inch void were oriented to provide a larger cross section (and thus a relatively larger scattered signal), while the rebar in the other void was oriented to provide a smaller cross section. The third rebar, which is perpendicular to and beneath the first two, begins to appear in Frame D and is visible through Frame $G$.

In the images shown here, the peak of the image intensity is coincident with the surface of a scattering target. In Figure 5, for the voids nearest the surface, the peak of the image appears in Frame $\mathrm{C}$ 
Frame A

- surface

Frame B

-1.4 " doep

Frame C

$-1.8^{\prime \prime}$ deep

Frame D

-2.1 " deep
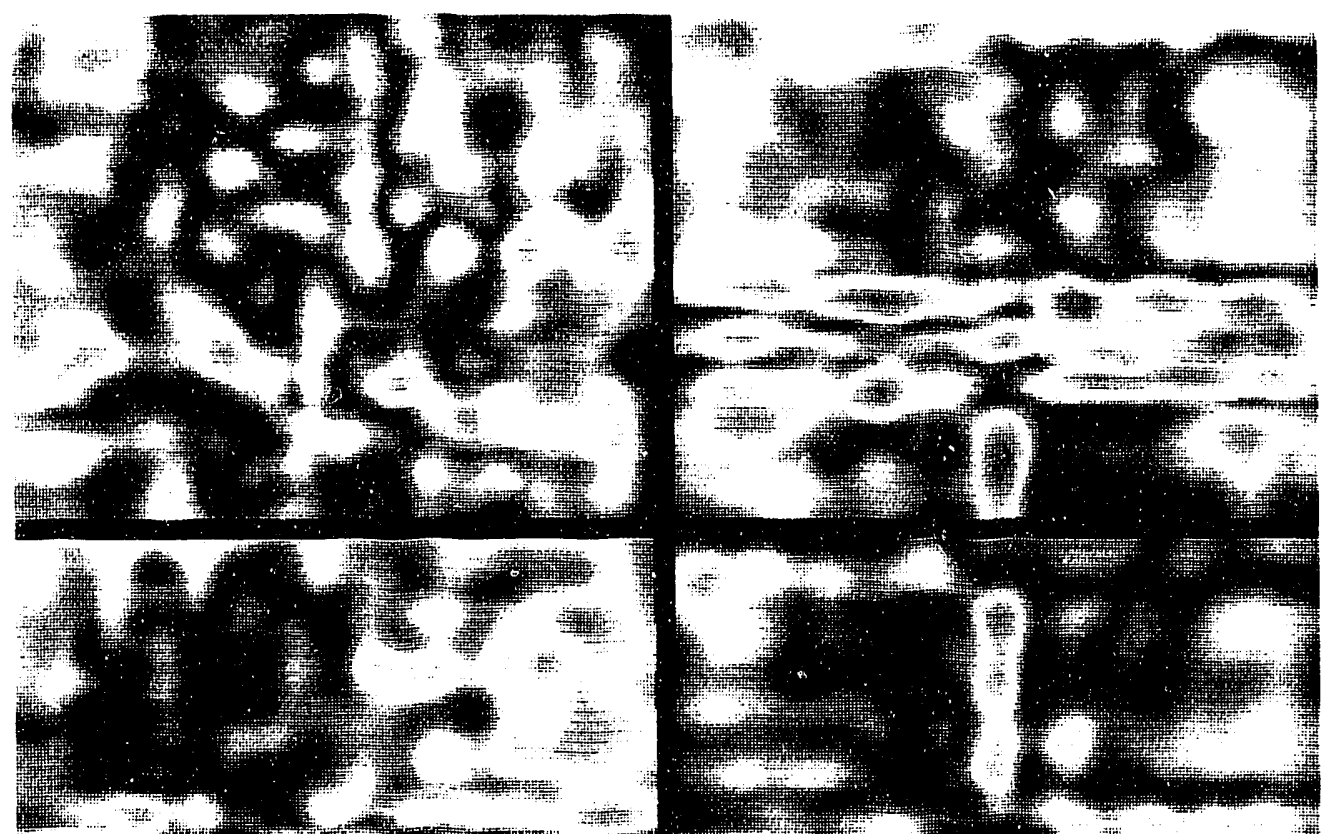

Frame E

2.t" deep

Frame F

-2.7" deep
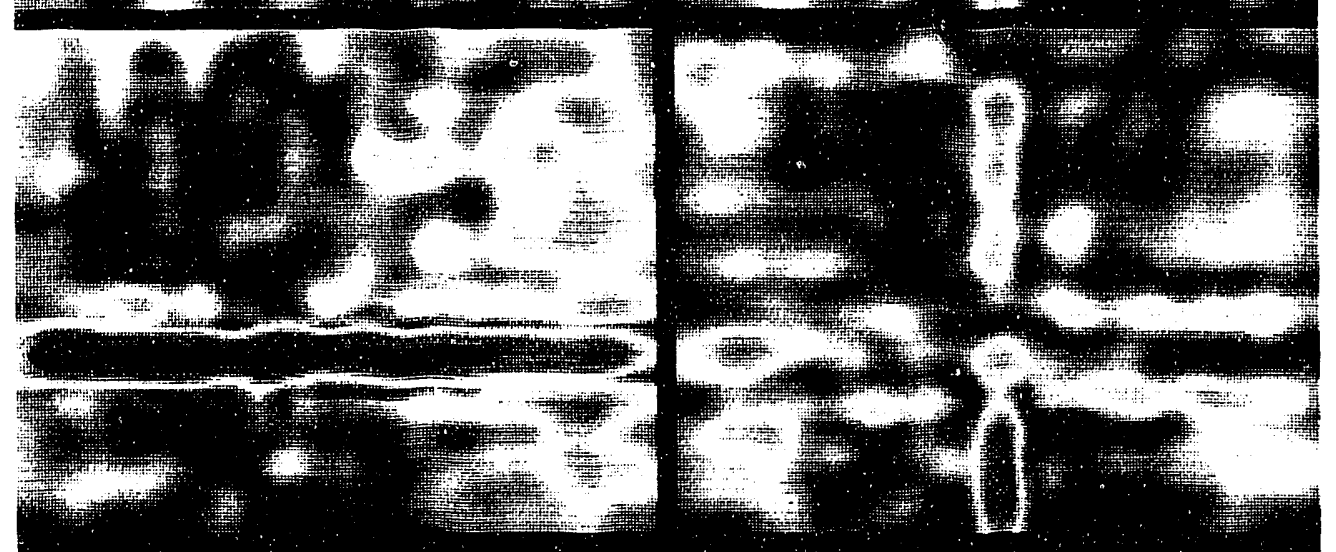

Frame $G$

$-3.3 "$ deep

Frame $\mathrm{H}$

$\sim 4.3^{\prime \prime}$ decp

Figure 5. Image sequence: $f$ cylindrical voids embedded in concrete 
Frame A

- surfaco

Frame B

$\sim 1$ " deep

Frame C

$\sim 1.8$ " deep

Frame D

$\sim 2$. 1" deep

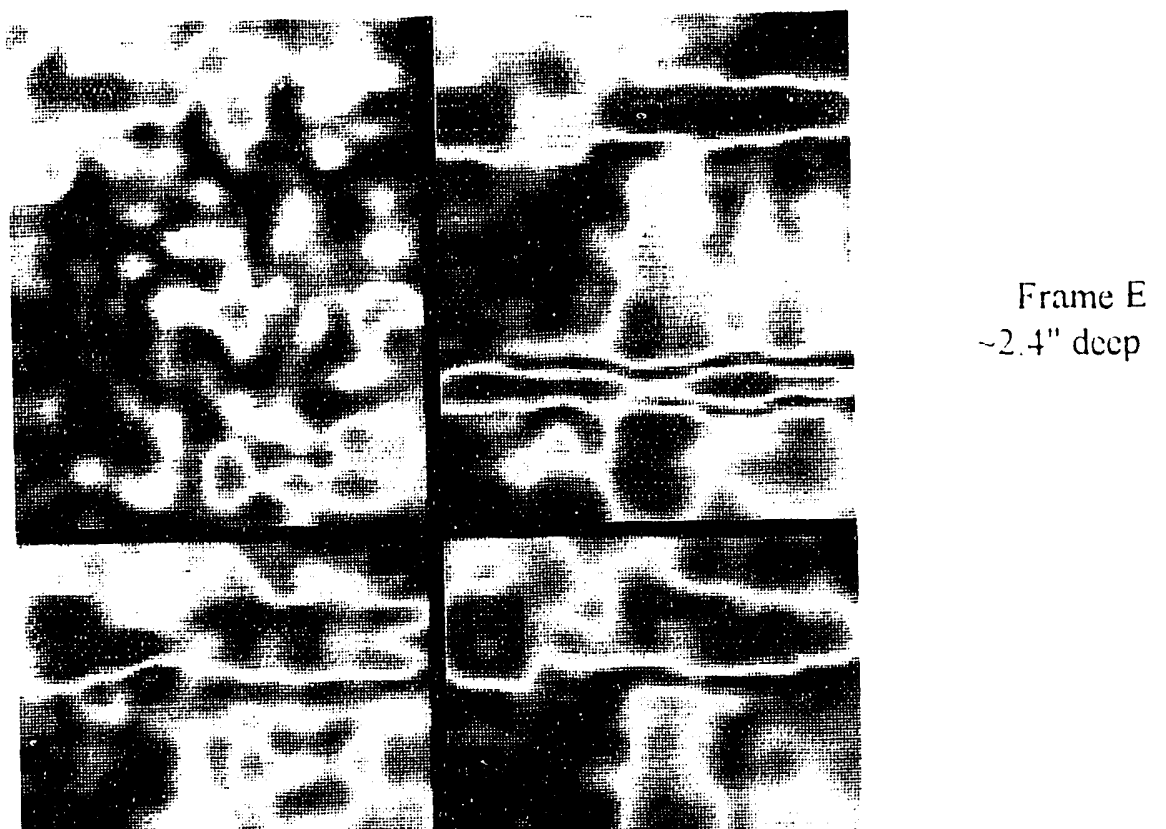

Frame F $-2.7^{\prime \prime}$ deep

Frame G

$-3.3^{\prime \prime}$ deep

Frame $\mathrm{H}$

$\sim 4.3^{\prime \prime}$ deep

Figure 6. Image sequence: 3 rebars embedded in concrete 
(a . oroximately 1.8 inches deep); in Figure 6 , the image intensity peak for the parallel rebars appears in Frame D (approximately 2.1 inches deep). Differences in location of image peaks for the voids and the rebars are caused by absolute differences in depths of the scattering surfaces of these objects. Air voids are formed using PVC pipe, and the void scattering surface occurs at the interface between the PVC pipe inner wall and the air void. For the removable rebar, the scattering interface is at the surface of the rebar, which is located some distance from the inner wall of the PVC pipe and slightly deeper ( 0.2 to 0.4 inches) in the concrete slab. Scattering from the removable rebars is also affected by the thin air layer that surrounds it.

Differences in calculated and actual locations are caused by errors in measurement and reconstruction processes. Error sources most likely to produce the largest discrepancies are the specification of the launch and receiving points within the antennas, with respect to the surface of the concrete. Other important error sources include inaccuracies in the estimated values of the electromagnetic properties for the concrete (frequency-dijendent properties like permittivity and attenuation), significant changes in these properties (which are assumed to be constant over any imaged volume) within an image volume, and deconvolution errors (deconvolution pulse not exact match to retum pulse).

Our current and on-going efforts are aimed toward developing and improving bistatic GPR hardware and imaging algorithms in preparation for our planned field test. Pulse generat: - $s$ with significantly higher output power ( 30 to 100 watts of peak output power) are currently under evaluation. These new generators will permit deeper penetration into the concrete and the use of bistatic antenna configurations and linear receiving arrays. Work is continuing to improve the accuracy of measurements and image processing and to develop methods for accurate estimation of material properties.

\section{Conclusions}

GPR combined with unique image reconstruction algorithms developed for identification and characterization of subsurface flaws and structural features has the potential for providing rapid and costeffective methods for large-area inspection of bridge decks and roadways. A basic inspection system design concept was developed at LLNL and is being used to guide the development of GPR hardivare and imaging algorithms. A laboratory testing capability, supported with both standard and specially developed equipment and extensive computational modeling capability, has been established to evaluate GPR components, subsystems, and systems. Recent test and image processing results have produced high quality reconstructed images of subsurface test objects. The results show that the basic inspection concept is feasible.

\section{References}

1. Infrasense, Inc., Final Report. Bridge Deck Evaluation Utilizing High Speed Rada", prepared for the New Hampshire Department of Transportation Bureau of Materials and Research, Cuncord. NH (November 1991).

2. K.R. Maser, T. Scullion, and R.C. Briggs, Use of Radar Technology for Pavement Layer Evaluation, Texas Transportation Institute. Colleze Station, prepared for Federal Highway Administration, Austin, TX (February 1991).

3. J.P. Warhus, J.M. Hernandez. S.D. Nelson. E.M. Johansson, and H. Lee, "Ground Penetrating, Imaging Radar for Bridge Inspection." Engineering Research. Development, and Technolugy Thrust Area Report FY-92, Lawrence Livermore National Laboratory, I.ivermore, CA UCRL 53868-92, (March 1993). 

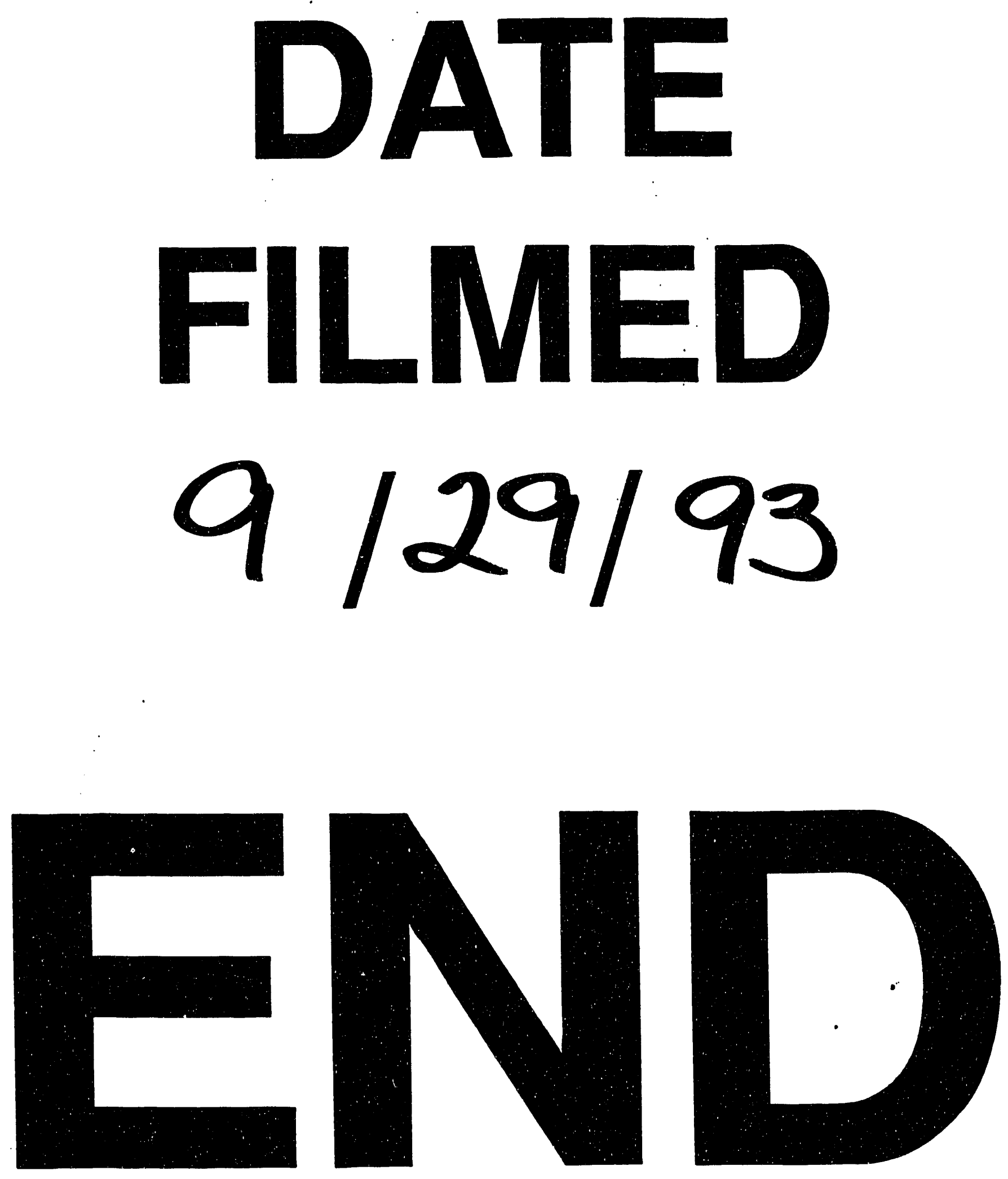
